\title{
La tipología urbanística alejandrina en la ciudad helenística
}

\author{
Joaquín Montero MuñIz *
}

\begin{abstract}
RESUMEN
En este artículo se realiza un acercamiento al urbanismo en la Antigüedad, y más en concreto al urbanismo regular aparecido en la antigua Grecia, que encuentra su máxima expresión y difusión con las conquistas territoriales de Alejandro Magno y, posteriormente, durante los reinos helenísticos.

La planificación y la fundación de nuevas ciudades durante la época helenistica no sólo es un agente motor de desarrollo económico, de control politico-militar del territorio o de difusión cultural, sino un factor muy importante y profundo de la propaganda política regia que más tarde seguirán empleando los emperadores romanos. Del mismo modo, también se analiza la importancia del número de ciudades que Alejandro fundara y la continuidad de ese modelo urbanistico regular a través

\section{ABSTRACT}

In this article is carried out an approach to the urbanism in the Antiquity, and specific to the planned urbanism in Ancient Greece, that finds its maximum expression and diffusion with Alexander's the Great territorial conquests and, later on, during the Hellenistic kingdoms.

The planning and foundation of new cities during the Hellenistic era are not only a motor of economic development, political and military control of the territory or cultural diffusion, but a very important and deep factor of the royal political propaganda that will be used later by the Roman emperors.

In the same way, it is also analyzed the importance of the number of cities founded by Alexander, the continuity of that urban pattern through the history and its
\end{abstract}

* Benedictine University. Lisle, Illinois (USA). 
de la historia, que ya contaba con destacados precedentes. Su influencia no sólo se plasmará en el mundo helenístico, sino también en la órbita del imperio romano. Concepción urbanistica para la planificación "ex-novo" de la que el mundo occidental es heredera. outstanding precedents. Their influence will not only be captured in the Hellenistic world, but also in the orbit of the Roman Empire. An urban model for the "ex novo" planning of which the Western world is the heir.

\section{PRECEDENTES: LA CIUDAD CLÁSICA GRIEGA}

Durante los siglos vi y $\vee$ a. C., los griegos, con el crecimiento de la ciudad-estado completado, crearian nuevas ciudades como colonias, capitales de estados federales o sustitución de otras ya existentes destruídas por las guerras. Ante estas necesidades constructivas o fundacionales, los antiguos helenos sentarian unas bases de planificación urbana en detrimento del crecimiento espontáneo y claramente desordenado que ya se había venido produciendo en otras ciudades ${ }^{1}$.

Aunque se desconoce cómo se comenzaron a aplicar por primera vez los nuevos métodos de planificación en las ciudades, no hay duda de que su origen se produjo en Jonia, en la costa oeste de Asia Menor y en particular en Esmirna y Mileto. En las colonias del oeste no existen demasiados indicios planificadores, o al menos no se realizaría de un modo sistemático y formal. Jonia, además, era una región geográficamente expuesta a las influencias urbanísticas, ideológicas y culturales del Este y Egipto?

De este modo, los grupos de colonos encontrarían en el sistema reticular la solución más simple a los problemas de distribución y parcelación de las nuevas tierras. El método rectangular o de damero fue el que ofreció menos complicaciones no sólo para los helenos y otros pueblos, sino, como sabemos, también para los romanos, herederos culturales de los

\footnotetext{
1 Tal es el caso de las ciudades-fortaleza, establecidas en lugares elevados para su mejor defensa, con la Acrópolis (ciudad alta), y el resto de la ciudad (ciudad baja), a sus pies y alrededores, típico del urbanismo arcaico, caracterizado este por la inclusión de las antıguas acrópolis como plazas fuertes y fortalezas-refugio, por el establecimiento de santuarios y por la disposición de plazas públicas (ágoras) que son el centro de la vida pública. Este urbanismo está marcado por el libre crecimiento y por las murallas que, al igual que las calles, siguen la forma del terreno para aprovechar los elementos topográficos en favor de su sistema defensivo. Roland Martin: Recherches sur l'Agora Grecque, París, 19651; ibidem: L'urbanisme dans la Gre'ce Antique, París, 1974.

Existen ejemplos de regularidad en planta y trazado en ciudades egipcias, como Kahun, Menfis o Tebas.
} 
griegos, que usarían la groma ${ }^{3}$ para dividir el parcelario agrario (las centuriaciones), trazar las principales arterias urbanas en las nuevas fundaciones o en sus asentamientos militares, muchos de los cuales evolucionarian dando origen a numerosas ciudades. Sobre la similitud del modelo campamental romano con el de Alejandro Magno se hablará más adelante. Es claro que es la repartición de la tierra el punto de partida para la planificación de la ciudad griega. Una vez consolidada la liberación del orden social feudo-aristocrático, la pólis de los ciudadanos y hoplitas exigia la asignación de tierras a los ciudadanos en las colonias, y así, una cuidadosa medición y reparto del suelo en estos asentamientos y en su periferia, tal y como refiere Frank Kolb: «El sistema de medición ortogonal se prestaba a ello y, evidientemente, se utilizó en las colonias, en las que, por ende, se haría una trazado regular de calles que dividiría en bloques de casas el área que iba a ser edificada. Con este procedimiento parecía lógico separar diligentemente el área prevista para obras públicas de las parcelas privadas ${ }^{4}$ ".

La colonización griega de Asia Menor comenzó en el siglo Xi a. C., estableciéndose la mayoria de las primeras ciudades en lugares elevados por razones defensivas. De estas fundaciones, Esmirna y Mileto ofrecen la evidencia más temprana para las ciudades griegas planificadas. Después de su destrucción a finales del siglo octavo antes de nuestra era por un terremoto, Esmirna fue completamente reconstruída siguiendo un nuevo sistema. La península sobre la que fue trazada se dividió en tiras mediante un sistema de calles paralelas. Se trataba, entonces, de un sistema callejero organizado, pero aún no era el típico plano ortogonal del urbanismo regular que aparecerá a lo largo de toda la historia en las ciudades de nueva planta, pues la ciudad de Homero no se reconstruiría siguiendo la forma de un tablero de ajedrez, ya que el aspecto externo que ofrecía la ciudad, rodeada de murallas, no era ni siquiera cuadrangular.

La ciudad de Mileto, sin embargo, sí que pasaría a la historia como un modelo de planificación urbana digno de elogio y de imitación. Su planificador, Hipódamo de Mileto (nativo de la misma), empleó un plano de cuadrícula para su reconstrucción tras ser destruída por los persas en 494 a. C., siendo también relacionado con la construcción del Pireo, el puerto

3 La groma era un instrumento agrimensor compuesto por una cruz de brazos iguales montada sobre un brazo móvil que la sostenía y unía a una vara vertical que la soportaba. De sus cuatro brazos colgaban contrapesos de bronce verticalmente. Se empleaba para trazar líneas rectas en la división del terreno.

4 Frank KolB: La ciudad en la Antigüedad. Gredos, Madrid, 1992. Pág. 102. 

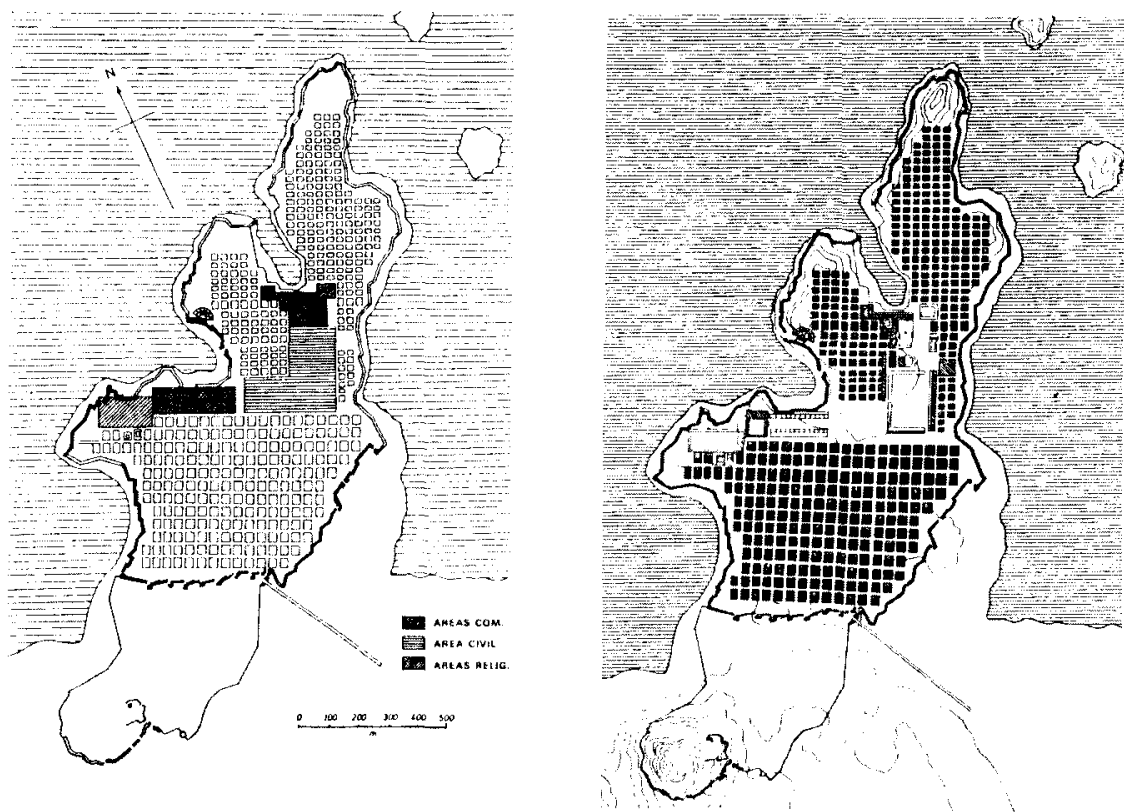

Fig. 1. Plano de Mileto. Diseñada por Hipódamo de Mileto en el siglo v a.C. Las "insulae" miden 100 pies por 175 pies (unos 30 por $52 \mathrm{~m}$.). En la figura derecha aparecen las distintas zonas de la ciudad.

ateniense, y otras ciudades como Sybaris, en el sur de Italia, o Rodas ${ }^{5}$. Lo que es indudable es que otras ciudades de este periodo poseen unas características comunes, como son la división del espacio en grandes áreas delimitadas por anchas calles principales, y subdivididas estas, a su vez, por un sistema cuadriculado de calles estrechas que se cortan, en la mayoría de los casos, en ángulos rectos (cuadrícula ortogonal). Además, las ciudades asociadas al nombre de Hipódamo, muestran un reparto espacial integrado por áreas no tan evidente en otras ciudades. Las diferentes zonas o distritos estaban diseñados para propósitos específicos: comercial, residencial, público, religioso, puertos, bahías, etc., con una clara tendencia a agrupar los edificios públicos. Es una planificación urbana basada en unos principios teóricos y matemáticos que en Rodas

Esto no está claro y los historiadores difieren al respecto. Parece ser que Hipódamo no hubiese podido tomar parte en las creaciones del Pireo y de Rodas, muy separadas en el tiempo, de no ser que hubiera sido un hombre extraordinariamente longevo, pero de su vida conocemos escasisimos detalles. 
también lleva a dividir la tierra en cuadros de tamaño predeterminado y uniforme.

Durante el período clásico tardío, la planificación urbana continuó basándose en el sistema hipodámico, aunque con ciertos matices originados por las necesidades orográficas, políticas, sociales o espaciales concretas de cada asentamiento, reduciéndose la distancia entre avenidas o empleando el paisaje como efecto visual en algunas ciudades construídas en terrazas, como Priene.

\section{ALEJANDRO COMO FUNDADOR DE CIUDADES}

Las conquistas de Alejandro Magno transformarian Grecia y el Oriente, pues tanto él como sus sucesores, fundarian numerosas ciudades como centros de control, administración y gobierno de los territorios conquistados, así como forma de difusión de la cultura y el modo de vivir heleno. Se puede decir que es a partir de este momento cuando surge un nuevo elemento condicionante en la fundación de ciudades: la propaganda. Pues no debemos olvidar que ya no estamos hablando de urbes erigidas por un sistema de gobierno democrático, sino por monarquías en las que los soberanos pretenden difundir su nombre, su imagen y sus obras por doquier, y la ciudad formará parte de ese culto a la propia imagen regia.

La influencia oriental será muy notable en el campo de la expansión de nombre e imagen, ya que los soberanos en las civilizaciones orientales, y tanto en la persa como en la egipcia, que los griegos conquistarian con Alejandro, eran deificados y recibían culto de sus súbditos, cosa que en un principio llamaría enormemente la atención de los compañeros del rey macedonio, pues estaban acostumbrados a tratarle como al primero entre iguales, según las costumbres de su ya entonces lejana Macedonia. Este cambio en la personalidad de Alejandro en la última etapa de su vida, en cierto modo obligado por las nuevas circunstancias políticas, religiosas y los enormes territorios conquistados, será la primera piedra del modelo de poder que se produce con las monarquías helenísticas y después con los emperadores romanos, donde el culto al soberano y la difusión de su imagen se tomarán como algo no sólo absolutamente lógico y normal, sino como esencial.

Por otro lado, en Alejandro se aprecia ya una temprana tendencia a la creación de nuevos núcleos poblacionales cuando sólo con dieciséis años, ausente Filipo del reino en una expedición militar contra Bizancio, y con el sello de la regencia en su mano, aplasta una rebelión tracia en Peonia, donde el muchacho toma la capital, de la que expulsa a sus habitantes, 
repoblándola con inmigrantes macedonios y dando a la nueva ciudad el nombre de Alejandrópolis. Este hecho pone de manifiesto la importancia que el nombre de un lugar adquiere para la propaganda, pues el joven Alejandro no desaprovecha la oportunidad de que se recordara quién sofocó la revuelta de los peonios dando su nombre a la antigua capital. Sin duda, esto es algo que aprendería sin salir de casa, pues su padre ya había dado su nombre a otras ciudades fundadas por él mismo ${ }^{6}$. Esto se va a convertir en algo habitual en los reinos helenísticos, sin olvidarnos que, con la influencia oriental, mayor será la práctica de este hecho. Por lo que se refiere a la planificación regular, Pella, la propia capital de Macedonia donde Alejandro nace, es una ciudad que "se trazó siguiendo un plano hipodámico, del que se han descubierto hasta tres calles perimetrales que se cortan en ángulo recto ${ }^{7}$ ". Con lo que Alejandro tiene el modelo a seguir de sus futuras fundaciones en su propia ciudad natal.

En principio, Alejandro fue reconquistando ciudades en Jonia a lo largo de la costa de Asia Menor y ocupándolas, dejando tras de sí y a medida que se adentraba en el imperio persa, una guarnición macedonia en ellas. Por lo tanto, en estas áreas ya urbanizadas, Alejandro no tendría la imperiosa necesidad de realizar nuevas fundaciones para dejar tropas en ellas o vertebrar política y militarmente el territorio. Será cuando de verdad se adentre en la parte del imperio persa más continental, y después de asegurarse las espaldas controlando todo el litoral mediterráneo oriental, cuando comience una organización y ocupación formal de los nuevos territorios que pasarian a su poder. Es, entonces, cuando la creación de ciudades se convierte en algo primordial para prolongar en el tiempo lo que sólamente unas victorias militares no podrían alargar, como el establecimiento de una organización política, el asentamiento de unas bases económicas, el control militar del territorio y el repoblamiento del mismo con colonos griegos y macedonios, factor este que llevará a una fusión de razas y a la importante transmisión de la cultura helénica por Oriente. De este modo, con la fundación de nuevas ciudades Alejandro obtendría respuesta a todas estas necesidades y además, inmortalizaba su nombre y dejaba una importante huella en el urbanismo de la zona.

Resulta una complejísima labor, casi un imposible, intentar no ya describir las numerosas Alejandrías, ya que no existen datos, sino el sólo

\footnotetext{
6 Filipópolis, fundada en Tracia por Filipo II en el centro de un sistema de caminos en 342 a. C. mezclando tracios con 2.000 macedonios y otros griegos.

José Miguel MUÑoz JiMÉnEz: La ciudad como obra de arte. Las claves del urbanismo en la Antigua Grecia. Ediciones Clásicas, Madrid, 1996. Pág. 81
} 


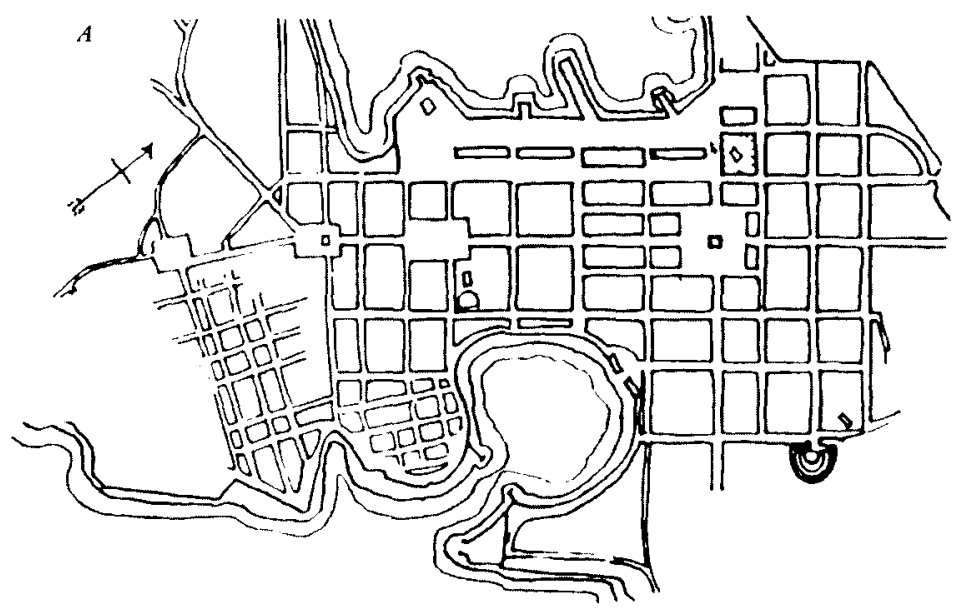

Fig. 2. El Pireo. Construido según el modelo hipodámico. No sigue un plano de módulos de igual tamaño en retícula como Mileto, pero se ajusta a los principios ortogonales llevados a cabo en Alejandria posteriormente.

hecho de enumerarlas con cierto rigor histórico, pues las fuentes de dónde procede nuestra información hoy en día son escasas, confusas y, a veces, hasta contradictorias. Aquí no va a realizarse una valoración de dichas fuentes o un estudio en profundidad sobre su fiabilidad, sino que se van a emplear para poner de manifiesto la ingente labor fundadora del soberano macedonio que, a pesar de que la información referente a sus ciudades, en la mayoría de los casos, no pasa de una simple mención en un texto, y no dispongamos de nada más completo, sí que queda de manifiesto históricamente hablando.

Aparte de las fuentes históricas tradicionales para el estudio de Alejandro Magno, como Arriano, Diodoro Sículo, Plutarco o Quinto Curcio Rufo -también Calistenes, quien acompañó a Alejandro en su expedición, aunque menos fiable-, que bebieron en las fuentes directas, ya perdidas, del relato de las conquistas de Alejandro basadas en las Efemérides redactadas por Eumenes, secretario real del soberano, y que su compañero Ptolomeo ${ }^{8}$ empleó para escribir una crónica histórica, contamos con

Ptolomeo, compañero y general de Alejandro, se convertirá en Ptolomeo I Sóter, soberano del Egipto helenístico tras la muerte de Alejandro. Los escritos de Ptolomeo, al igual que las Efemérides Reales de Eumenes de Cardia, enorme archivo de cuanto acontecia, se perdieron. Sin embargo, el historiador romano Arriano conoció y utilizó los escritos de Ptolomeo para escribir su 
una serie de fuentes literarias que P. M. Fraser explora en su obra Cities of Alexander the Great ${ }^{9}$.

Fraser realiza un recuento y listado no de las Alejandrías que Alejandro fundara en el transcurso de sus campañas según sus historiadores, sino las que aparecen mencionadas en las fuentes que emplea. De los numerosos autores y obras que cita destacan inicialmente tres: el Epitome de Estefano de Bizancio, la versión griega superviviente más temprana de El Romance de Alejandro, propiamente llamada Vida de Alejandro de Macedonia, y las listas encontradas en las Crónicas del Mundo y los Anales del período imperial. Estas fuentes son coincidentes en muchos puntos y nos sirven para considerarlas de un modo general, aunque cada grupo de ciudades del listado presente diferentes problemas, pues todas ellas proceden del origen común de la literatura popular alejandrina.

Estéfano de Bizancio enumera dieciocho Alejandrías junto a otras dos ciudades: Bucefalia y Nikeia. Su relación es más numerosa que la que aparece en el Romance, donde aparecen trece. Las diferencias entre los tres grupos de materiales que Fraser estudia residen fundamentalmente en el número e identidad de las Alejandrías de los historiadores y geógrafos, pero esto no es lo que aqui nos interesa analizar, sino, como se ha dicho anteriormente, la labor fundadora de un soberano y su influencia posterior. No es difícil de imaginar que todas las Alejandrías que aparecen en las crónicas correspondieran a verdaderas fundaciones que luego cambiaron su nombre con el paso del tiempo, perdiéndose la principal referencia para su identificación, pues sirva de ejemplo que, en la parte más oriental del imperio de Alejandro, las Alejandrias evolucionaron a Iskandariyas, porque el nombre de Alejandro, tanto en literatura árabe como oriental es Iskander. En todo caso, y siguiendo a Fraser ${ }^{10}$, la suma total de las diferentes ciudades enunciadas por historiadores, geógrafos, el Romance, la tradición popular irania y otras fuentes, completa un número de cincuenta y siete, cantidad que aunque parezca excesiva debemos respetar, pues está documentada en unas fuentes escritas que, mayor o menormente fiables, existen. Aparecen asi, en esa lista -además de Bucefalia y Nikeia entre otras-, las siguientes Alejandrías:

Anábasis de Alejandro Magno, quizás la fuente más directa y fiable de toda la historiografía alejandrina, con lo cual, aunque de forma indirecta y mutilada, ha llegado a nosotros.

P.M. Fraser: Cities of Alexander the Great. Oxford, 1996.

10 P.M. Fraser: $O b$. cit. Págs. 240-243. 


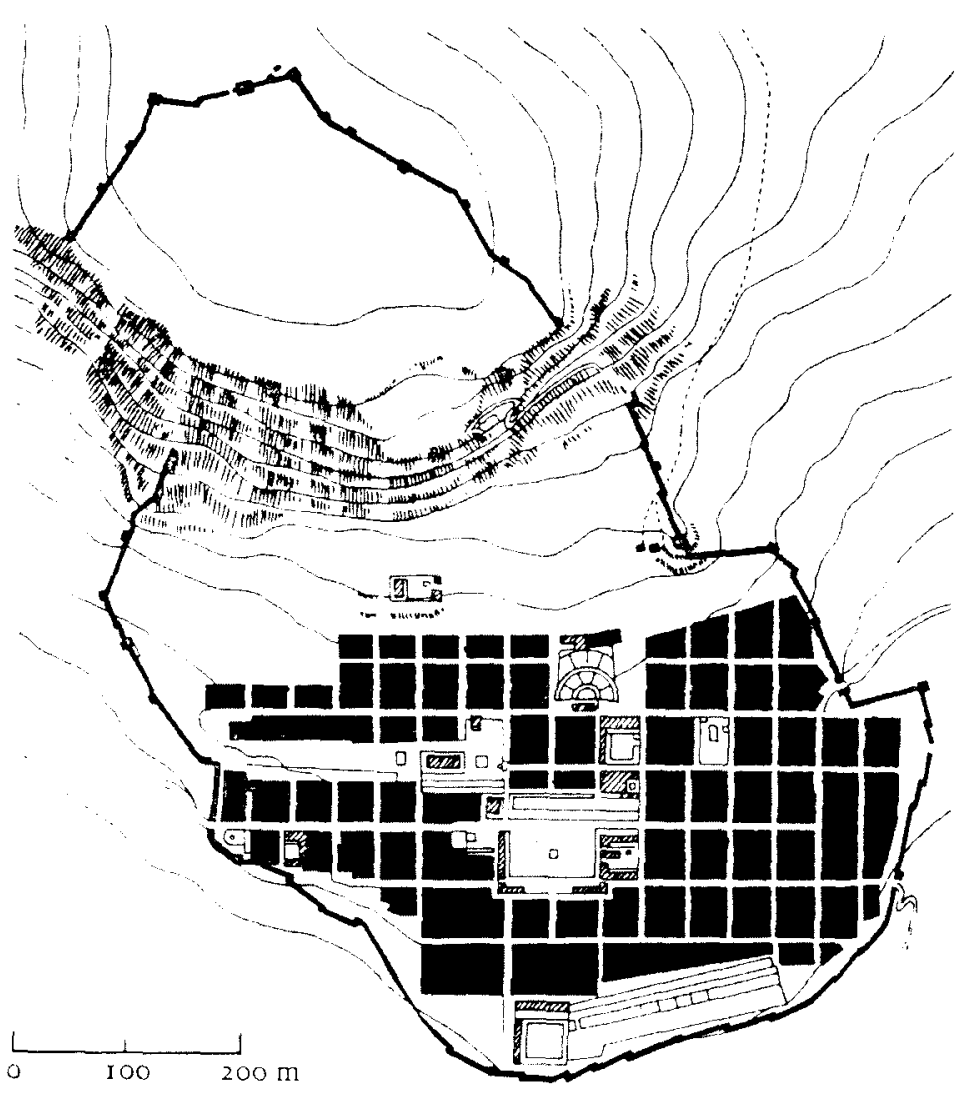

Fig. 3. Plano de Priene, fundada hacia 350 a.C., con las insulae, que median 120 por 150 pies (unos 35 por 45 metros), en negro.

- Alejandrescata (o Alejandría Escate).

- Alejandría en Aracosia.

- Alejandría en Aria (Herat).

- Alejandría en Babilonia (Seleucia en el Hedipon).

- Alejandría junto a Bactria.

- Alejandría junto al Golfo Negro (Alejandrópolis ?).

- Alejandría en Caria.

- Alejandría en Carmania.

- Alejandría del Cáucaso (Paropamisadas).

- Alejandria en Cilicia (Alejandría Isos). 
- Alejandría en Cirenaica.

- Alejandría en Egipto.

- Alejandría del Gránico.

- Alejandría en el Indo.

- Alejandría en Macedonia o Tracia (Alejandrópolis).

- Alejandría en Makarene.

- Alejandría en Margiana (Antioquía en Margiane).

- Alejandría de Mesopotamia (Antioquia en Migdonia).

- Alejandría en el monte Latmos (Alabanda-Antioquía).

- Alejandría en Oxiana.

- Alejandría en Opiana (Opian).

- Alejandría en Orítide.

- Alejandría-Rambacia.

- Alejandría en Sakastán.

- Alejandría en Escitia.

- Alejandria-Spasinou (Alejandría Cárax).

- Alejandría Sogdiana.

- Alejandría de Susa (Seleucia en el Eulaios).

- Alejandría en el Tigris (Seleucia en el Tigris).

- Alejandria Troas.

- Alejandría en el Xantos.

$Y$ otras tres o cuatro ciudades más con el nombre de Alejandrópolis.

Sirva esto para entender la enorme labor fundacional del rey de Macedonia, que pasa a ser soberano del imperio persa y faraón de Egipto. Sus ciudades aparecen a lo largo del itinerario de sus campañas por numerosos motivos. La mayoría de las veces son campamentos militares que se fortifican y transforman en ciudades habitadas por los soldados más veteranos que encuentran en ellas descanso a su servicio o campamentos-hospitales donde se cuidaba a los heridos y mutilados de las batallas. Otras buscarian distintas finalidades, como Bucefalia, que honraba la memoria de su caballo Bucéfalo a la muerte del mismo conteniendo su tumba. Respecto al número de ciudades creadas por Alejandro, algunos autores ponen abiertamente en duda los números demasiado altos, como Walbank 11: "En todas las tierras que atravesara en su marcha fundó Alejandrías, no setenta, como aseguraba Plutarco ${ }^{12}$, pero sí un número

F. W. Walbak: El mundo helenistico. Taurus. Madrid, 1985. Pág. 40.

12 "Alejandro fundó más de 70 ciudades entre los bárbaros y sembró el Asia de instituciones helénicas." (PLUTARCO: Moralia, 328 c. Sobre la fortuna de Alejandro, 1). 


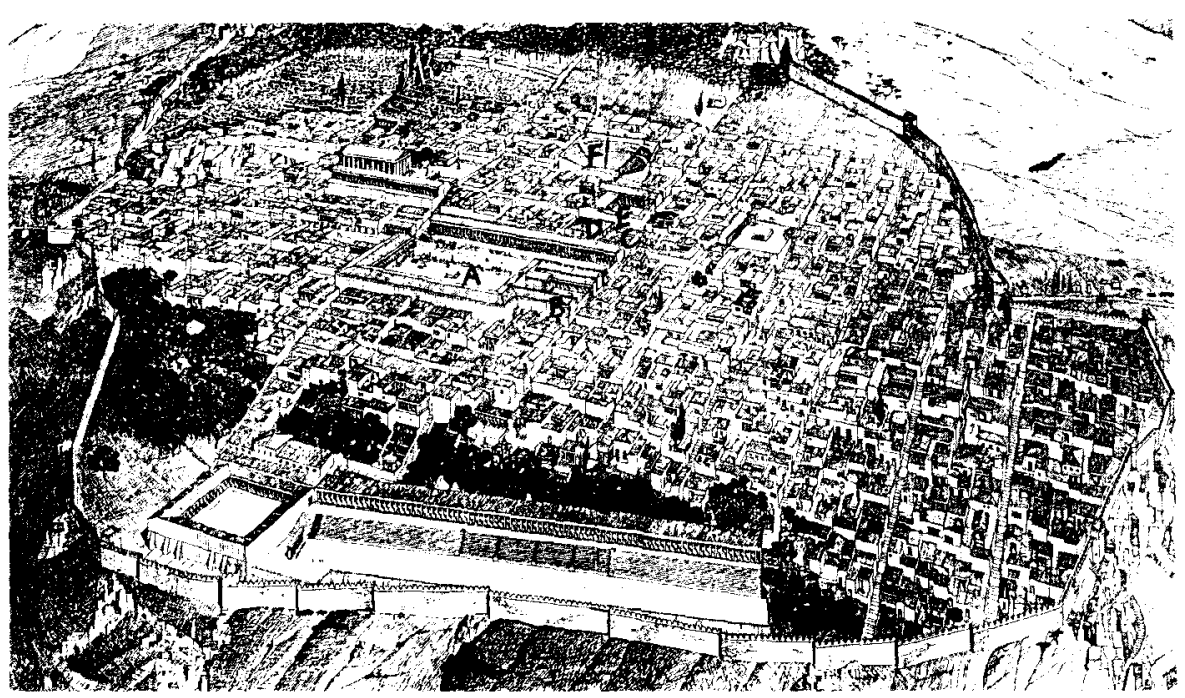

Fig. 4. Vista de Priene. A, ágora. B, templo de Asklepios. C, pritaneo. D, gimnasio. F, teatro.

importante, quizá una veintena en total, es particular al este del Tigris, donde hasta entonces los centros urbanos habian sido escasos. La mayor parte de estas fundaciones no son más que nombres en unas listas, nombres oficiales por lo demás, que no siempre fueron aquellos por los que serían conocidos en años posteriores. Esas ciudades debian servir a una amplia variedad de objetivos: algunas debian defender puntos estratégicos, puertos o vados, otras vigilarian regiones más amplias; todas estas fundaciones presuponian la existencia de un territorio adecuado para mantener a los colonos y, preferentemente, una población nativa que pudiera ser obligada a realizar los trabajos agrícolas. Algunas se convertirian más tarde en centros comerciales, en tanto que otras encontrarian la decadencia para perecer después."

En lo que se refiere a la morfología de estos asentamientos, disponemos de fuentes arqueológicas escasas, pero con el material existente podriamos elaborar una teoría, si no exacta, bastante aproximada a la realidad que demostraría la continuidad urbana regular con origen campamental desde Alejandro hasta los romanos y posteriormente. La katoika era un modelo de asentamiento militar que en muchos casos adquiria el rango de ciudad, iniciado por Alejandro para establecer en él guarniciones de soldados, en su mayoría veteranos, que además de colonizar el territorio con su establecimiento en él, beneficiándose del reparto de lotes de tierras, sivieran de contingente de fuerza en el control del territorio si fuese necesario. Aunque 
poseamos descripciones de las mismas -ciertamente escasas-, estas poblaciones han desaparecido sin dejar rastro alguno, pero sí pueden ser consideradas como el prototipo de las ciudades de guarnición romana y posteriores. Siendo, además, ampliamente empleadas después de Alejandro: «Estos asentamientos militares cumplian una finalidad triple. A diferencia de los de Alejandro, estaban constituídos principalmente por soldados en activo y no por veteranos. Por lo tanto, proporcionaban una reserva militar de hombres entrenados con los que el rey podía contar en el caso de producirse una guerra. En tiempos de paz actuaban como guarniciones que mantenian el orden y defendían posiciones vulnerables contra una posible invasión y también llevaban a cabo sus tareas de paisanos, en especial el cultivo de la tierra ${ }^{13}$." Esta organización del territorio llevada a cabo por Antígono III no parece ser algo novedoso, sino una continuidad de lo que Alejandro ya había comenzado a hacer no sólo con veteranos, sino también con tropas jóvenes, mercenarios y contingentes persas que servían en su ejército tras la conquista de su imperio. "Sin embargo, no todas las katoikiai anatolias eran asentamientos militares. Existen registros de varias docenas de katoikiai civiles, muchos de cuyos miembros, si no la mayoría de ellos, provenían de la población indígena y se hallaban en condiciones de ser llamados a filas, si surgía la necesidad, como los kátoikoi militares. Por desdicha en muchos casos no es posible saber con certeza de qué clase de katoikiai se trata. Las katoikiai identificables como militares se encuentran sobre todo en Asia Menor occidental, tanto en el territorio seleúcida como en el de Pérgamo ${ }^{14}$." En su organización, la katoika se asemejaría mucho a una aldea, unidades fundamentales de la estructura social y de la producción, aunque las aldeas estuvieran habitadas por campesinos. Si estos asentamientos estaban habitados por macedonios, podían ser promovidos a la condición de ciudad, estableciéndose entonces una nueva estructura administrativa y mayores ventajas. ¿Pero qué es lo que más nos interesa para este estudio de ese tipo de asentamientos, ya sean civiles o militares? Su forma; perfectamente regularizada y planificada. El riguroso plano rectilíneo que ofrece y que sentará unas bases urbanístico-campamentales que van a repetirse en el mundo helenístico, extendiéndose también por el norte de África, para ser luego expandido, de modo similar, por los romanos.

Pero de la enorme lista de Alejandrias que Alejandro Magno fundara durante la conquista y organización del imperio persa, la más importante y duradera en el tiempo es la Alejandría de Egipto que hoy conoce-

F.W. WAlbank: Ob. cit., pág. 120

F.W. WALBANK Ob. cit., págs. 120-121. 


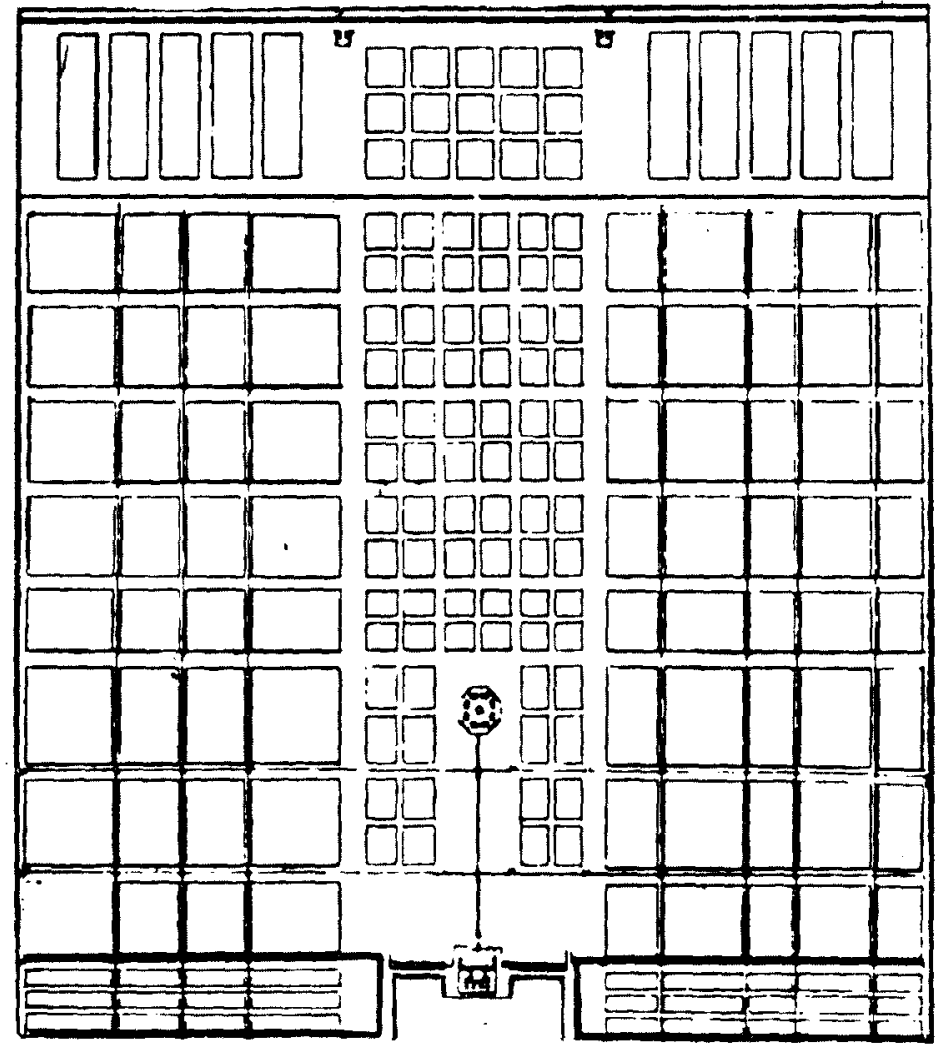

Fig. 5. Farahabad, fortificación militar persa reconstruida en el s. XVII sobre los restos de varias ciudades fortificadas sucesivas. Es similar a una katoika de Alejandro Magno, pues este plano corresponde estrictamente a las descripciones históricas de la katoika, prototipo de las ciudades-campamento posteriores.

mos, la que fue capital del Egipto helenistico de los Ptolomeos y modelo cultural y científico del mundo antiguo que en nuestros días se pretende recuperar, o al menos emular en la medida de lo posible, con la creación de la nueva biblioteca de Alejandría. Para su fundación, en la que el joven rey macedonio se dejó guiar por un sueño, se escogió un lugar totalmente virgen de la desembocadura del Nilo, en el mismo delta, y Dinócrates, su arquitecto, trabajaría con el propio soberano en la elaboración de sus planos, aunque el encargado de su ejecución fue Cleomenes de Naucratis. La ciudad, fundada en 331 a.C., sería perfeccionada y completada por la dinastía de los Ptolomeos. El plano de la 
ciudad (en forma de clámide o manto rectangular) está en función del sistema de vías de comunicación, donde las formas ortogonales se ajustan a las variaciones topográficas entre el mar abierto y un gran lago litoral alimentado por el Nilo, el Mareotis, que ha ido secándose con el paso del tiempo desde el siglo XVI. Pronto alcanzaría un crecimiento poblacional extraordinario, con 300.000 habitantes que eran hombres libres (lo que hace suponer una población total en torno al millón), llegando a ser la urbe más importante del mundo antiguo, sólo superada después por Roma, aunque con un componente mucho más cosmopolita que esta (con gente de todas las razas, pero especialmente griegos y judíos).

Sus calles eran de gran amplitud, llegando las principales a alcanzar una anchura de treinta metros, y más estrechas las menores (entre seis y siete metros). La Apámeia corría de norte a sur a lo largo de mil quinientos metros y media treinta y cuatro metros de ancho, contando sus dos porches columnados, de siete metros de profundidad a cada lado. Sus insulae eran de 330 por 278 metros y formaban un reticulado como el de las demás ciudades planificadas ortogonales.

Pero Alejandro no vería completarse la realización de su programa urbanístico, tan sólo contaría con tiempo para las operaciones primarias de canalización y sistematización a escala territorial y el trazado y establecimiento de las infraestructuras esenciales para abrir las nuevas ciudades al desarrollo tanto social como económico. Serán sus sucesores los que continúen con una intensa labor urbanizadora por todo el Oriente próximo, desarrollando muchas de estas recientes fundaciones y creando muchas otras más ${ }^{15}$.

\section{CONTINUIDAD EN EL URBANISMO HELENISTICO}

Con la temprana muerte de Alejandro a los 32 años, en 323 a. C., su imperio se divide en partes tras largas y sangrientas guerras entre los que habian sido sus amigos, sus compañeros y sus generales. Lo que habia conseguido el joven rey de forma meteórica, en tan sólo diez años, desde que cruzara el Helesponto y pusiera su pie en Asia, se iba a desmoronar también con enorme rapidez, sin embargo su legado tanto militar como

15 Sobre Alejandria hay una abundante biliografia (Arriano III, 1,5) recogida en AA.VV.: Alexandrie 9. $\| l^{\mathrm{e}}$ siecle av. J.C. Tous les savoirs deu monde ou le rêve d'universalite des Ptolémées dir. Christian Jacob y F. de Polignac. París 1992. 


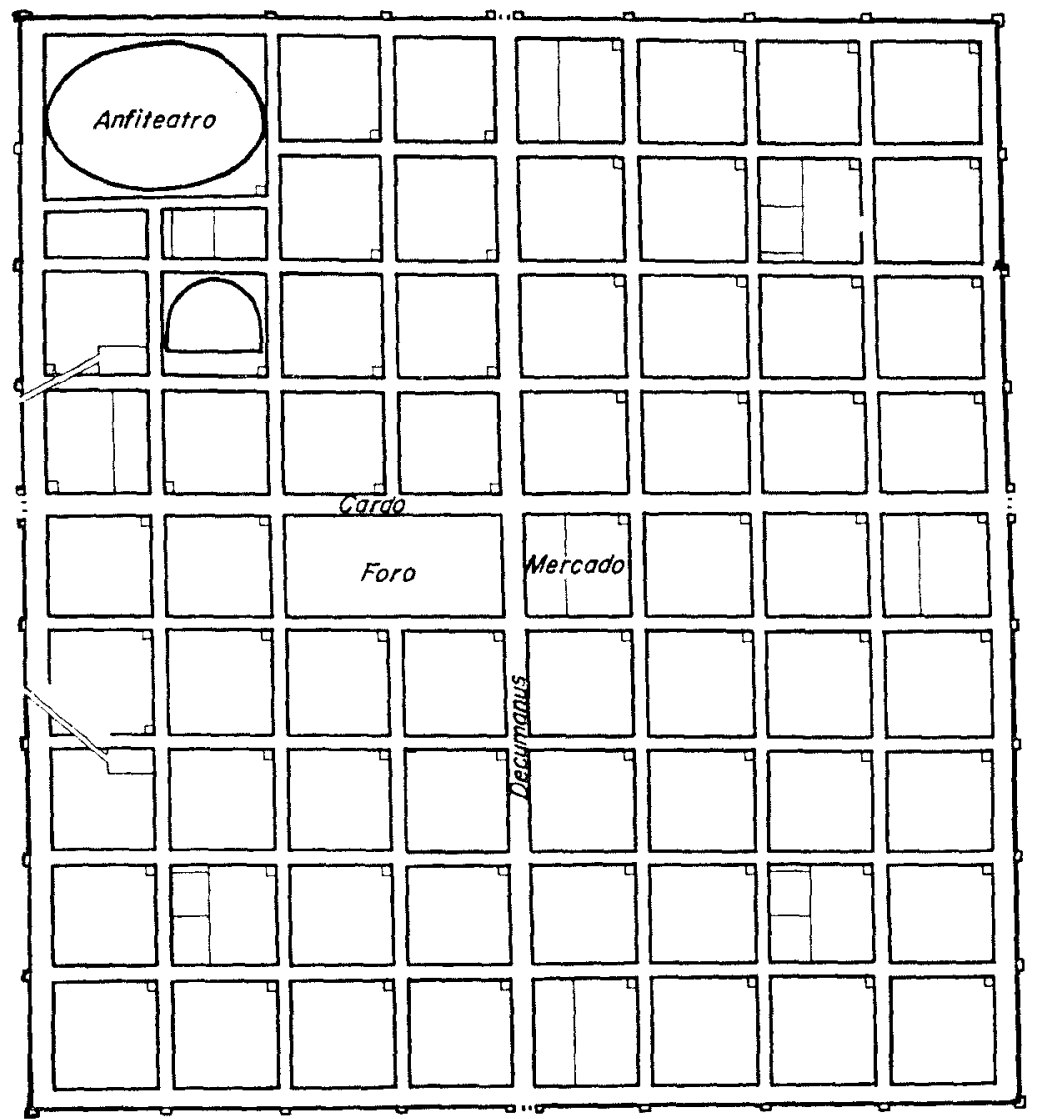

Fig. 6. Esquema de la ciudad como derivada del campamento romano, segun Torres Balbás.

de organización territorial, y su huella en el urbanismo, iban a quedar patentes durante mucho más tiempo.

«En el Oriente griego la planta hipodámica tuvo una repercusión extraordinaria favorecida por la fiebre fundacional de los monarcas helenísticos, singularmente los Seleúcidas", asegura García Bellido ${ }^{16}$. Así, las dos monarquías helenísticas más importantes, los Lágidas en Egipto, y muy espe-

16) Antonio Garcia Bellido: Urbanistica de las grandes ciudades del mundo antiguo. C. S. 1. C., Instituto Español de Arqueologia. 2. ed., Madrid, 1985. Pág. 85. 


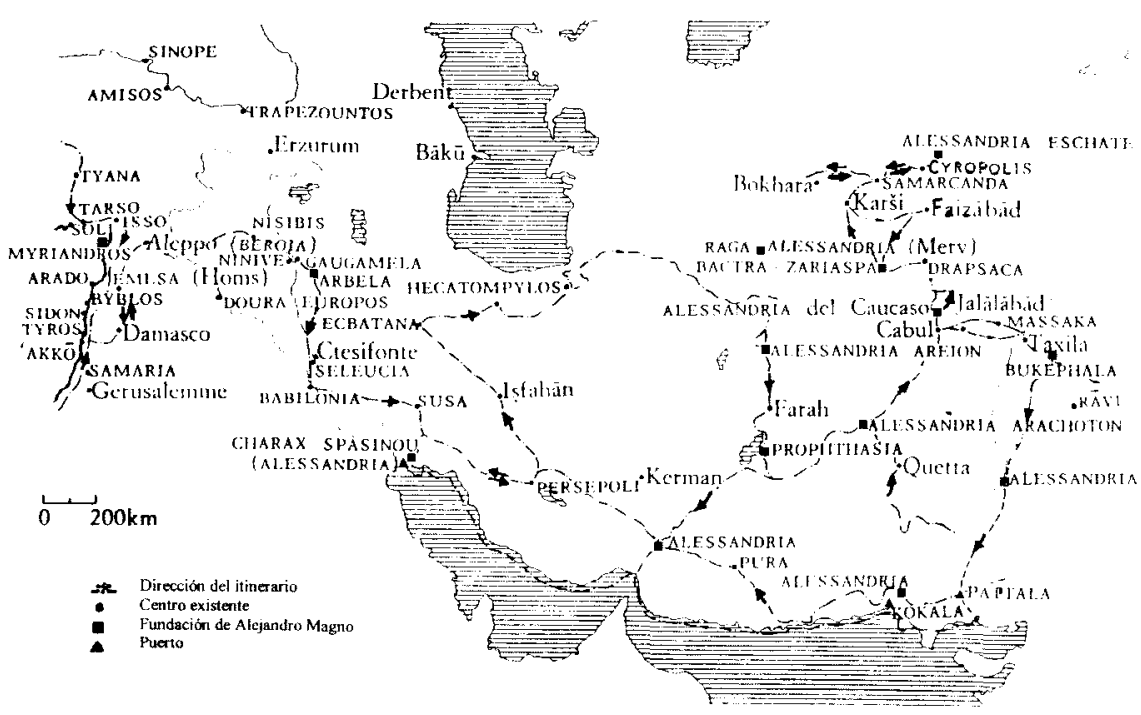

Fig. 7. Itinerario de Alejandro Magno y ciudades fundadas (M. Coppa).

cialmente los Seléucidas -en quienes nos detendremos aquí- en Mesopotamia, Siria y Anatolia, urbanizarian sus reinos intensamente ${ }^{17}$.

"La fundación de una cadena de ciudades griegas nuevas, que se extendía sobre todo el ámbito de sus dominios, desde Bactria y Sogdiana en el lejano oriente, es el logro más asombroso de la dinastía Seléucida. A diferencia de las antiguas ciudades de Grecia y del Asia Menor occidentai, por lo común estaban trazadas según un esquema ortogonal, teniendo en cuenta, no obstante, la topografía del emplazamiento; un buen ejemplo nos lo brinda Priene ${ }^{18}$." Va a llevarse a cabo una intensa labor de colonización para la definitiva integración de los enormes territorios conquistados durante la época alejandrina en los nuevos reinos que los gobiernan.

"Seleuco fundó ciudades por toda la extensión del territorio que gobernaba. A dieciséis las llamó Antioquía, con el nombre de su padre, a cinco, Laodicea, por el de su madre, a nueve, con el suyo y a cuatro con los de sus mujeres (esto es, a tres, Apamea y a una, Estratonicea). A las demás

17 Sobre las fundaciones en estos territorios: LERICHE, P.: Un rempart Hellensttique en Asie centrale Revue Archéololique, Paris, 1974, págs. 231-270.

18 F. W. Walbank: Ob. Cit., pág. 121. 


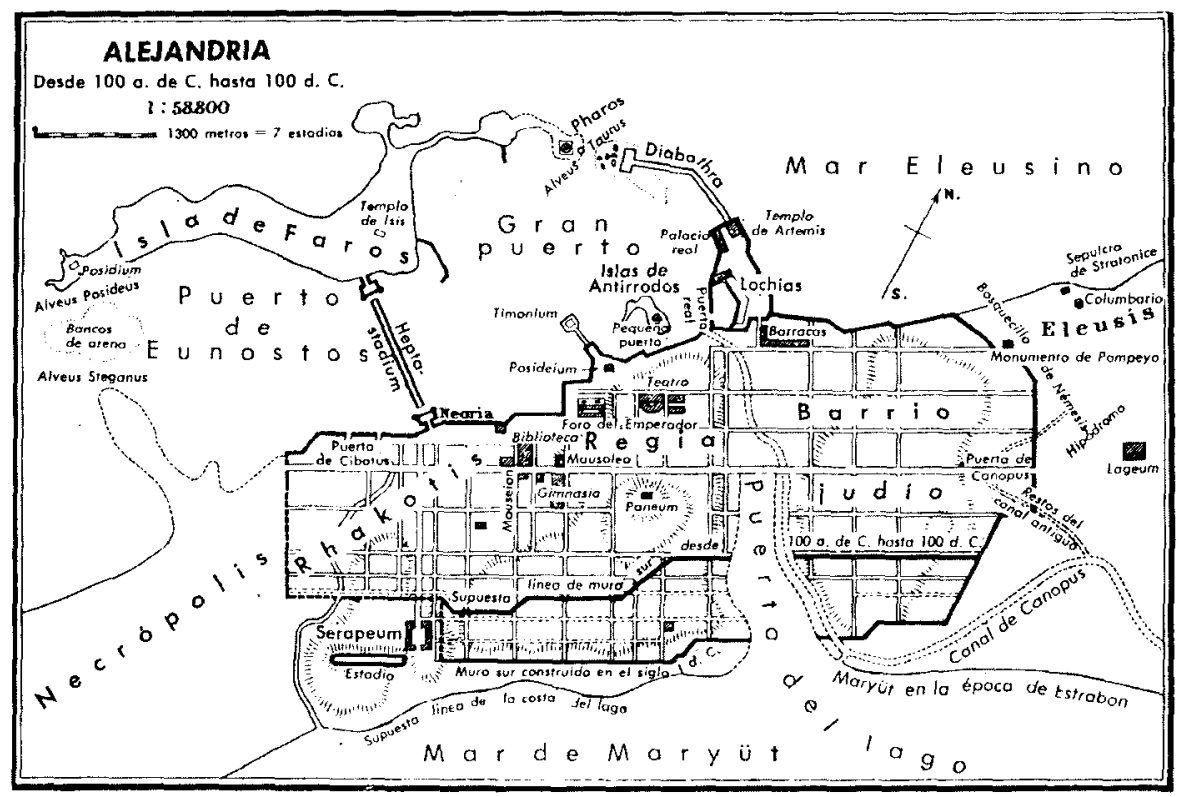

Fig. 8. Alejandria de Egipto (según W. Sieglin. Instituto Geográfico de Wagner \& Debes, Leipzig).

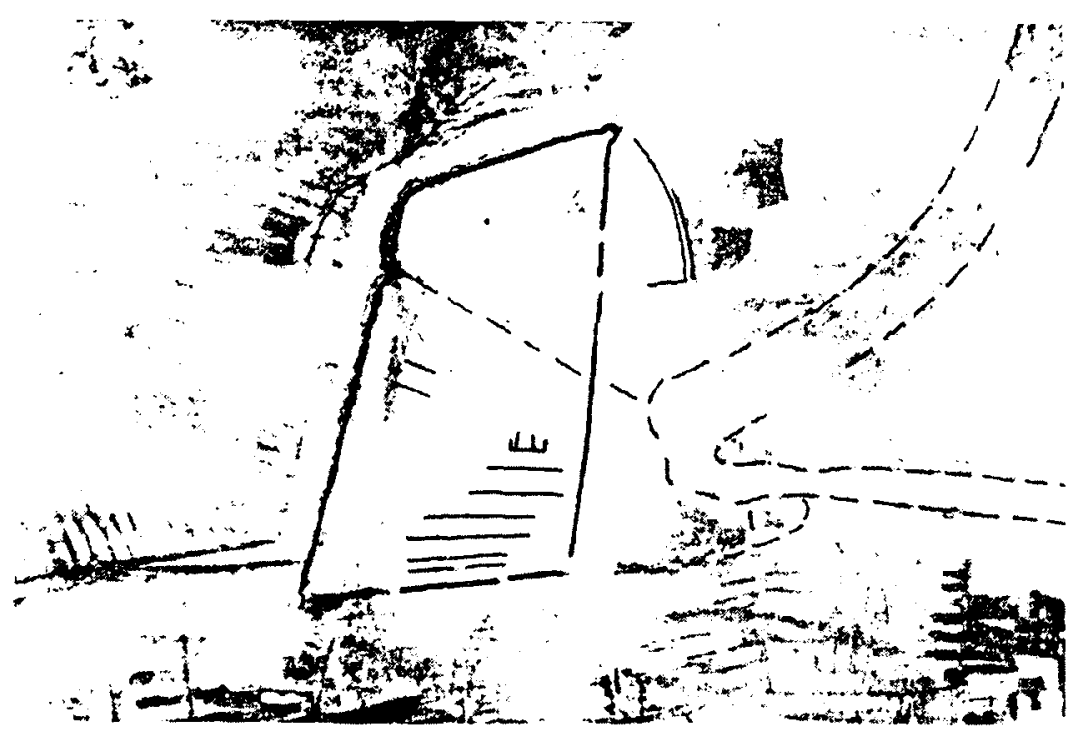

Fig. 9. Esquema de Alejandria de Susa (M. Coppa). 


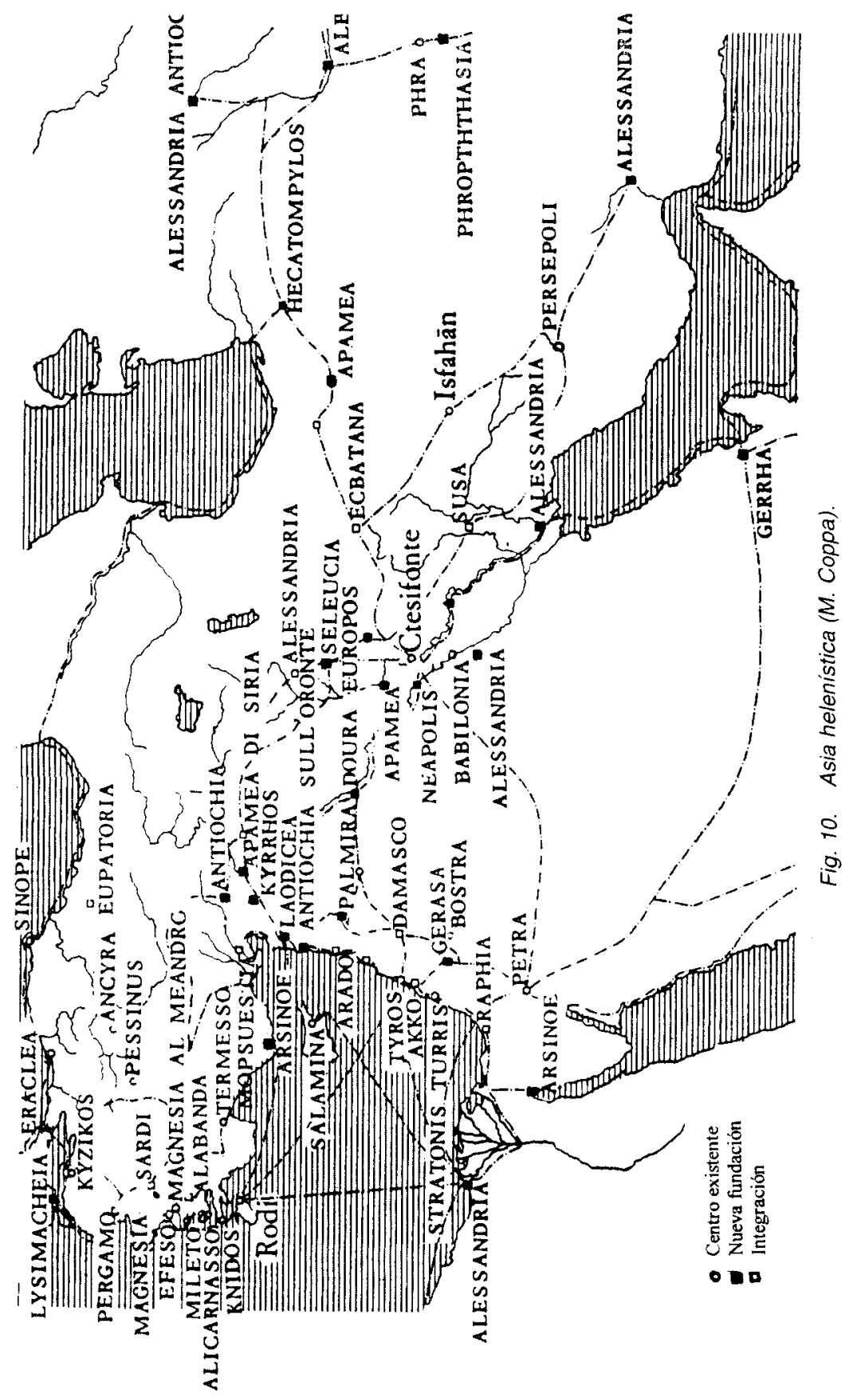


les dio nombres tomados de Grecia o Macedonia o de sus propias hazañas o en honor de Alejandro ${ }^{19}$." Todas estas nuevas urbes se establecian por voluntad del rey y a sus expensas, pagando él la construcción y las murallas, aportando el suministro de agua y las provisiones para el primer



Fig. 11. Area principal de la cultura Seléucida (M. Coppa).

19 APIANO: Syriaca, 57. 




Fig. 12. Laodicea del Mar (Siria). Fundada en el 270 a.C.

año y realizando repartimientos de lotes de tierras entre los ciudadanos, hechos que además de resultar toda una demostración de poder y riqueza, eran una propaganda política excelente.

Afortunadamente, podemos disponer de mucha mayor información sobre las ciudades helenisticas posteriores a Alejandro que sobre las suyas propias, lo que hace pensar que la mayoría no llegaron a alcanzar un elevado grado de desarrollo, perecieron relativamente pronto en el tiempo o cambiaron su nombre. Estos datos son especialmente generosos sobre las ciudades Seleúcidas de Siria. Y aunque la mayor parte de los detalles de la colonización de las mismas no esté registrado, la importancia poblacional de los elementos griego y macedonio pueden deducirse, en ocasiones, de los nombres de las mismas, tomados de regiones y ciudades de Macedonia y Grecia. En el norte de Siria podemos apreciar Europus, Berea, Edessa, Cyrrus, Perinto, Maronea, Apollonia; en Palestina, Dión y Pella; en Persis, Tanagra y Maitona, etc. Lo mismo ocurrió en América con los españoles y otros europeos colonizadores, dando 
nombres de lugares, pueblos y ciudades de la madre patria a las nuevas tierras y asentamientos fundados.

Las grandes ciudades de la dinastía Seleúcida fueron: Antioquía, la capital, sobre el Orontes. Una de las mayores metrópolis del mundo antiguo junto con Roma, Alejandría y Constantinopla. Fue fundada por Seleuco I Nicanor y nombrada así en recuerdo de su padre Antíoco. De planta regular, con calles cortándose en ángulo recto formando manzanas de 112 por $58 \mathrm{~m}$., en una proporción de 1:2, la más usual en las ciudades seleúcidas y la misma con la que estaba trazada Pella, capital de Macedonia. La atravesaba una gran avenida como eje principal de unos 20 estadios de longitud (unos tres kilómetros y medio), con aceras porticadas (de $10 \mathrm{me}$ tros de anchura) por columnas de granito gris y rosa separadas entre si cinco metros, es decir, unas 1.400 columnas en total; canales de desagüe para el agua y una calzada de grandes losas calizas de casi 10 metros para el tráfico, con lo que la anchura total, incluyendo aceras, era de 30 metros ${ }^{20}$.

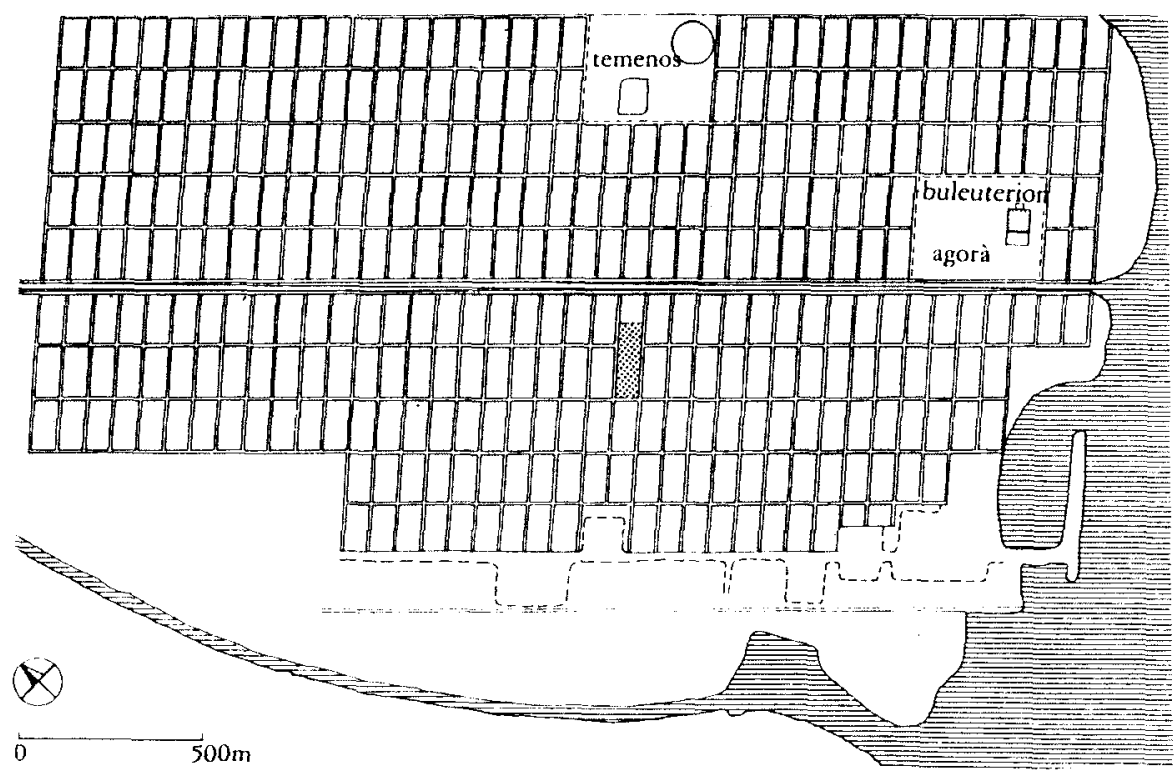

Fig. 13. Seleucia die Tigris. Reconstrucción (M. Coppa).

20. Estrabon, XVI, 2-4. Libanio, Anhoco III pág. 110; Welskopf, E.C.: Hellenistiche Poleis, $r$ vol. Berlín, 1974. 
Aunque Seleucia, en Pieria, sería uno de los puertos principales, Laodicea del Mar y Apamea sobre el Orontes, serian grandes centros militares donde se mantenían la caballeria y los elefantes de guerra. Apamea sería creada por Seleuco Nicanor en 286 a. C., dándole como nombre el de su esposa Apame. Con una extensión de 205 ha., también de trazado regular, cortándose sus calles en ángulo recto, una longitud de kilómetro y medio, corriendo de norte a sur, en su vía principal porticada y espaciadas sus calles laterales entre si en más de 100 metros, tendría menos importancia que Antioquía.

Laodicea también fue fundada por Seleuco I Nicanor, dándole el nombre de su madre Laodice. Tenía 220 ha. de extensión en un plano reticular, con



Fig. 14. Dura Europos (Siria), junto al Éufrates. Fundada en el 300 a.C. 
el cruce de calles en ángulo recto formando manzanas de 112 por $58 \mathrm{~m}$., igual a las de Antioquia, con una vía principal porticada cortada por otras transversales más estrechas pero también porticadas.

Seleucia del Tigris, en Babilonia, donde murió Alejandro, fue la fundación más antigua realizada por Seleuco, convirtiéndose en el centro administrativo y de influencia greco-macedonia de Mesopotamia. Pero existen innumerables ciudades fundadas por la dinastía en todas las zonas del reino, como Laodicea del Líbano y Antioquía de Cyrrestice en Siria; otra Apamea que controlaba el paso del Éufrates en Zeugma, Antioquia-Nibisis en Migdonia, Antioquia-Edessa en el recodo del Éufrates, Seleucia en Susiana, Seleucia del Mar Eritreo (Golfo Pérsico), Apamea en Mesene, Antioquia en Persis, y otras ciudades antiguas que tomarian apariencia griega y serían rebautizadas, como Susa, que se convirtió en Seleucia del Euleus, además, muchas otras Alejandrias y Antioquias constituirian una segunda fundación, incluso Babilonia fue nuevamente fundada en tiempos de Antíoco IV.

Este rosario de fundación de nuevas ciudades que se llevó a cabo por todo el Oriente griego, pone de manifiesto la mentalidad típicamente helenística de expansión territorial y control de los dominios, planificación del espacio y explotación de la riqueza que supone la tierra y aprovechamiento del comercio con la creación, a su vez, de nuevos caminos y vías de comunicación. Se trata, además de vertebrar el territorio, y de dejar -en segunda instancia-, un sello personal en él que sirva para la promoción personal y la propaganda, pues del mismo modo que en el arte se multiplican los retratos de los soberanos, en la vida proliferan las ciudades que subrayan el carácter personal del gobierno de los mismos y de su familia. Ideas estas que, indudablemente, mostrarán una acentuada continuidad más tarde con el imperialismo romano.

\section{BIBLIOGRAFIA}

ARRIANO: Anábasis de Alejandro Magno (vol. 1 -Libros I-III-y vol. 2 -Libros III-VIII -). Gredos. Madrid, 1982.

BENÉVOLO, L.: Diseño de la ciudad, 2. El arte y la ciudad antigua. Gustavo Gili. México, 1979.

BILlows. R.A.: Antigonos the One-Eyed and the Creation of the Hellenistic State. University of California. Berkeley, 1997

Boswoth. A.B.: Alejandro Magno. Cambridge University, 1996.

CAStagnOLI, F.: Orthogonal town Planning in Antiquity. MIT Press. London, 1971.

COHEN. G.M.: The Hellenistic Settlements in Europe, the Islands, and Asia Minor. University of California. Berkeley, 1995.

COPpA, M.: Storia dell'urbanistica. Le etá ellenistiche. (2 vols.) Officina Edizioni. Roma, 1981

Curcio Rufo, Q.: Historia de Alejandro Magno. Gredos. Madrid, 1986.

DRorsen, J.G.: Alejandro Magno. Fondo de Cultura Económica. México, 1988. 
ENGEIS, D.W.: Alexander the Great and the Logistics of the Macedonian Army. University of California. Berkeley, 1980.

FRASER. P M.: Cities of Alexander the Great. Clarendon. Oxford, 1996.

GARCIA y BELLIDO A.: Urbanística de las grandes ciudades del mundo antiguo. C.S.I.C., Instituto Español de Arqueología. 2." ed., Madrid, 1985.

HaMmOND. N.G.L.: Alejandro Magno. Rey, general y estadista. Alianza. Madrid, 1992.

HoLTF, L.: Alexander the Great and Bactria. The Formation of a Greek Frontier in Central Asia. E.J. Brill. New York, 1995.

HOMO, L.: Alejandro el Grande. Biografías Gandesa. Barcelona, 1973.

JoUguet, P.: Alexander the Great and the Hellenistic World. Macedonian Imperialism and the Hellenization of the East. Ares. Chicago, 1985.

KolB, F.: La ciudad en la Antigüedad. Gredos. Madrid, 1992.

MülLeR, W. y VOGEL, G.: Atlas de Arquitectura, 1. Alianza Atlas. Madrid, 1996.

MUNOZZ JIMENEEZ, J.M.: La ciudad como obra de arte. Las claves del urbanismo en la Antigua Grecia. Ediciones Clásicas. Madrid, 1996.

Murray, O. \& Price. S.: The Greek City (From Homer to Alexander). Clarendon. Oxford, 1998.

Rykwet, J.: The ldea of a Town: The Anthropology of Urban Form in Rome, Italy and the Ancient World. MIT Press. London, 1988.

SHIPLEY, G.: The Greek World after Alexander. 323-30 B. C. Routledge. New York, 2000.

SIDKY. H.: The Greek Kingdom of Bactria: From Alexander to Eucratides the Great. University Press of America, 2000.

VV.AA.: Misurare la terra: centuriazione e coloni nel mondo romano. Panini. Roma, 1983.

Walbank. F.W.: Historia del Mundo Antiguo. El mundo helenístico. Taurus. Madrid, 1985.

WARD-PERKINS. J.B.: Cities of Ancient Greece and Italy. Planning in Classical Antiquity. George Braziller Publishers. London, 1974.

WYCHERLEY, R.E.: How the Greeks Built Cities. The relationship of architecture and town planning to everyday life in ancient Greece. Norton. New York, 1976. 